
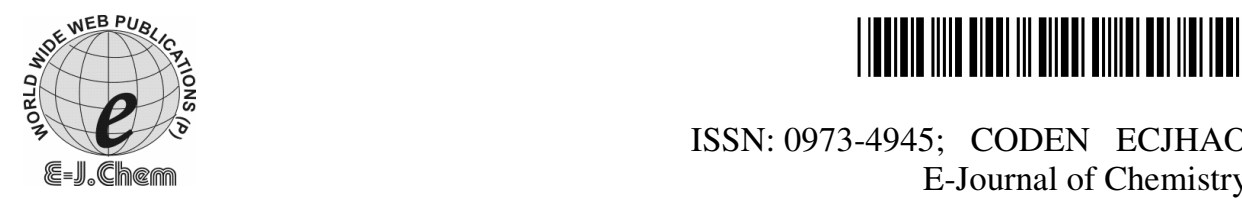

ISSN: 0973-4945; CODEN ECJHAO

E-Journal of Chemistry

http://www.e-journals.net

Vol. 5, No.3, pp. 641-647, July 2008

\title{
A Simple and Mild Acylation of Alcohols, Phenols, Amines, and Thiols with a Reusable Heteropoly Acid Catalyst $\left(\mathrm{H}_{6} \mathrm{P}_{2} \mathrm{~W}_{18} \mathrm{O}_{62} \cdot 24 \mathrm{H}_{2} \mathrm{O}\right)$
}

\author{
GUSTAVO P. ROMANELLI ${ }^{\S *}$, DANIEL O. BENNARDI ${ }^{\S}$, \\ JUAN C. AUTINO ${ }^{\S}$, GRACIELA T. BARONETTI ${ }^{\#}$ and HORACIO J. THOMAS ${ }^{\S}$ \\ ${ }^{*}$ Centro de Investigación y Desarrollo en Ciencias Aplicadas (CINDECA), \\ Facultad de Ciencias Exactas, Universidad Nacional de La Plata-CONICET. \\ Calle 47 No 257, B1900JK La Plata, Argentina \\ ${ }^{\S}$ Cátedra de Química Orgánica, Facultad de Ciencias Agrarias y Forestales, \\ UNLP. Calles 60 y 119, B1904AAN La Plata, Argentina \\ \# Departamento de Ingeniería Química, Facultad de Ingeniería, Universidad de Buenos \\ Aires. Ciudad Universitaria, C1428BGA Buenos Aires, Argentina \\ Fax: 54221 4254533; gpr@quimica.unlp.edu.ar
}

Received 1 June 2007; Accepted 1 August 2007

\begin{abstract}
The acylation of alcohols, phenols, thiols, and amines with varied substitution using acid anhydrides is efficiently catalyzed by WellsDawson heteropoly acid $\left(\mathrm{H}_{6} \mathrm{P}_{2} \mathrm{~W}_{18} \mathrm{O}_{62} \cdot 24 \mathrm{H}_{2} \mathrm{O}\right)$. Reactions proceed with very good to excellent yield in air at room temperature, using toluene as solvent (40 examples). The bulk catalyst was easily reused without appreciable loss of its activity.
\end{abstract}

Keywords: Acylation; Alcohols; Amines; Heteropolyacid; Phenols; Thiols; Wells-Dawson catalyst.

\section{Introduction}

Hydroxyl and amino groups are widely occurring functional groups in molecules in nature, and they can also be found in a number of compounds of biological and synthetic significance ${ }^{1}$ including flavonoids, steroids, carbohydrates, amino acids, nucleosides, etc. Protection of alcoholic and phenolic hydroxyl groups is currently required, acetylation being one of the most general reactions. Different procedures can be applied ${ }^{2}$, involving an acid chloride or acid anhydride with a base ${ }^{3-6}$, or an acid anhydride in the presence of an acid catalyst. Homogeneous catalysts currently used for this purpose are $p$-toluenesulfonic acid and sulfamic acid $^{7 \mathrm{a}}$ and a variety of Lewis acids including simple salts ${ }^{7 \mathrm{a}-\mathrm{g}}$ and various triflates ${ }^{7 \mathrm{a}, \mathrm{c}, \mathrm{h}}$, Besides, iodine ${ }^{7 \mathrm{a}}, \mathrm{NBS}^{8 \mathrm{a}}, \mathrm{Sc}\left(\mathrm{NTf}_{2}\right)^{3,8 \mathrm{~b}}$ acetylimidazole ${ }^{8 \mathrm{c}}$, and $\mathrm{PPh}_{3} / \mathrm{CBr}_{4}{ }^{8 \mathrm{~d}}$ have been employed as catalysts for achieving alcohol acetylation and formylation. 
Amines and thiols are acylated using Lewis acids as catalysts, for example $\mathrm{LiCl}^{7 \mathrm{~d}}$ $\mathrm{Mg}\left(\mathrm{ClO}_{4}\right)_{2}{ }^{7 \mathrm{e}}$, or $\mathrm{InCl}_{3}{ }^{7 \mathrm{~g}}$. In spite of their efficiency, the above mentioned soluble catalysts have some disadvantages: industrial use of mineral acids leads to serious environmental problems due to highly acidic waste streams; Lewis acids are efficient as catalysts but most of them are wasteful because they are usually hydrolyzed during the isolation, and triflates are generally expensive.

In recent years there has been great interest in the reactions performed under heterogeneous catalysis, because of the possibility of recovering and recycling the acid catalyst, largely reducing the environmental impact. A diversity of noncorrosive materials have been used as heterogeneous catalysts. Some of them are zeolite HSZ-360 ${ }^{9 \mathrm{a}}$ and zirconium sulfophenyl phosphonate ${ }^{9 b}$, used for acetylating alcohols/phenols. Nafion- $\mathrm{H}^{9 \mathrm{c}}$ is useful for acetylating alcohols, amines and thiols, while alcohol acetylation/formylation can be achieved by using the heteropolyacid and the corresponding salt ${ }^{9 \mathrm{~d}, \mathrm{e}, \mathrm{f}}$. In general, the reactions have proved to be simpler and cleaner.

Heteropolyacids are constituted by a close-packed framework of metal-oxygen octahedra $\mathrm{MO}_{6}\left(\mathrm{M}=\mathrm{Mo}^{6+}, \mathrm{W}^{6+}\right)$ surrounding a central atom $\mathrm{X}\left(\mathrm{Si}^{4+}, \mathrm{P}^{5+}\right)$. Wells-Dawson (WD) catalyst ${ }^{11,12}$ exhibits superacidic properties, and can be used in bulk or supported form in reactions requiring electrophilic catalysis. We have employed WD acid for performing aldehyde $^{13 \mathrm{a}}$ and other alcohol/phenol ${ }^{13 \mathrm{~b}}$ protection and deprotection and, more recently, for catalyzing the Pechmann reaction ${ }^{13 \mathrm{c}}$.

In the present letter we report a catalytic procedure for easily acylating a variety of primary and secondary alcohols, phenols, amines, and thiols with $\mathrm{Ac}_{2} \mathrm{O}$ at room temperature in toluene. This procedure can also be used for preparing phenyl and alkyl esters from other acid anhydrides, under heterogeneous catalysis by bulk WD acid.

\section{Experimental}

\section{General Procedures}

Commercially available alcohols, phenols, thiols, and amines, Aldrich or Fluka, were distilled or recrystallized before use. ${ }^{1} \mathrm{H}-\mathrm{RMN}$ spectra $\left(\mathrm{CDCl}_{3}\right)$ were recorded on Bruker $200 \mathrm{MHz}$ spectrometer using TMS as internal standard. Low-resolution mass spectra were recorded on a Perkin Elmer GC-MS model (Q-MASS 910). Spectral data agree with the expected values. The purity determination of most of the products was accomplished by GC analysis on a Perkin Elmer instrument and TLC on silica gel 60 F254 plates, for co-injection with authentic samples prepared by known methods. The purity established by GLC was better than $97 \%$ in all the cases.

The Dawson acid $\left(\mathrm{H}_{6} \mathrm{P}_{2} \mathrm{~W}_{18} \mathrm{O}_{62} .24 \mathrm{H}_{2} \mathrm{O}\right)$ was prepared by the Drechsel method from a $\alpha / \beta \mathrm{K}_{6} \mathrm{P}_{2} \mathrm{~W}_{18} \mathrm{O}_{62} \cdot 10 \mathrm{H}_{2} \mathrm{O}$ isomer mixture. This Dawson-type salt was prepared according to the technique reported by Lyon et al ${ }^{11}$. Concentrated $\mathrm{H}_{3} \mathrm{PO}_{4}$ in a $4: 1$ acid/salt ratio was added to a boiling aqueous solution of $\mathrm{Na}_{2} \mathrm{WO}_{4} \cdot 2 \mathrm{H}_{2} \mathrm{O}$, and the mixture was kept boiling in a reflux system for $8 \mathrm{~h}$. The salt was precipitated by adding $\mathrm{KCl}$, then purified by recrystallization and cooled overnight to $278 \mathrm{~K}$. The product, which is a mixture of the $\alpha$ and $\beta$ isomers, was filtered, washed and then vacuum-dried for $8 \mathrm{~h}$.

The acid ${ }^{12}$ was obtained from an aqueous solution of $\alpha / \beta \mathrm{K}_{6} \mathrm{P}_{2} \mathrm{~W}_{18} \mathrm{O}_{62} \cdot 10 \mathrm{H}_{2} \mathrm{O}$ salt, which was treated with ether and concentrated $\mathrm{HCl}(37 \%)$ solution. The Dawson acid so released formed an addition compound with the ether, which allows it to be separated from the solution. After obtaining the ether solution with the acid, the ether was eliminated by flowing dry air and the remaining solution was placed in a vacuum desiccator until crystallization. 
General procedure for the acylation of alcohols, phenols, amines, and thiols

A mixture of alcohol, phenol, amine or thiol $(1 \mathrm{mmol})$, toluene $(1 \mathrm{~mL})$, acetic anhydride $(1.5$ mmol) and WD catalyst ( $1 \mathrm{mmol} \%, c a .44 \mathrm{mg}$ ) was stirred at room temperature for the stated time (Tables 1-4). The catalyst was removed by filtration and was then washed with toluene $(1 \mathrm{~mL})$. The solution was concentrated and the residue was generally subjected to column chromatography on silica to give the desired alkyl acetates, aryl carboxylates, amides or thiol esters.

All the products were identified by comparison of analytical data (TLC, mp, IR, NMR) with those reported or with authentic samples prepared by the conventional method.

\section{Results and Discussion}

Reaction conditions were optimized varying temperature, anhydride:substrate and WDacid:substrate ratios, the amount of catalyst, and the reaction time. Experiments for checking the reutilization of the catalyst showed almost no decrease in yields over three successive batches. In these experiments the catalyst was washed with toluene and was then reused in subsequent reactions.

\section{Acetylation of alcohols}

Primary alcohols (Table 1) acetylate with better yields (entries 1, 2 and 5) than secondary alcohols (for example, entries 3 and 8) showing the importance of the steric factor. The best yield of 1-decyl acetate was attained at $c a .1 \mathrm{~h}$ of reaction at room temperature. Shorter and longer times gave somewhat lower yields. Besides, using 5\% catalyst and keeping other reaction conditions unchanged, or when a double amount of $\mathrm{Ac}_{2} \mathrm{O}$ was used, yields were 1-2\% higher than the values recorded in Table 1.<smiles>[R]C([R])O</smiles>

1

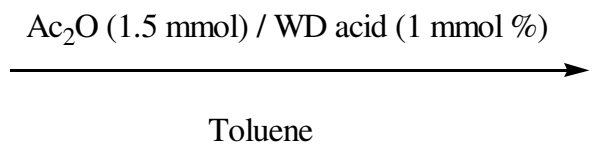

Toluene<smiles>[R]C([R])OC(C)=O</smiles>

2

Table 1. WD-Acetylation of alcohols with $\mathrm{Ac}_{2} \mathrm{O}$

\begin{tabular}{|c|c|c|c|c|}
\hline Entry & $\mathrm{R}^{1}$ & $\mathrm{R}^{2}$ & Reaction time, $\mathrm{h}$ & Yield of $2, \%$ \\
\hline 1 & $n-\mathrm{C}_{9} \mathrm{H}_{19}$ & $\mathrm{H}$ & 1 & 96 \\
\hline 2 & $\mathrm{PhCH}_{2} \mathrm{CH}_{2}$ & $\mathrm{H}$ & 1 & 99 \\
\hline 3 & $\mathrm{PhCH}_{2} \mathrm{CH}_{2}$ & $n-\mathrm{C}_{3} \mathrm{H}_{7}$ & 1 & 93 \\
\hline 4 & $\mathrm{PhCH}_{2}$ & $\mathrm{Me}$ & 1 & 93 \\
\hline 5 & $\mathrm{Ph}$ & $\mathrm{H}$ & 0.75 & $98^{\mathrm{a}}$ \\
\hline 6 & $\mathrm{Ph}$ & $\mathrm{Ph}$ & 1 & 97 \\
\hline 7 & & & 1 & 93 \\
\hline 8 & & & 1 & $85^{\mathrm{b}}$ \\
\hline
\end{tabular}

${ }^{a}$ Yields of isolated product over three subsequent batches were 97, 96, and $96 \%$, respectively.

${ }^{b}$ For each mmol of cholesterol, $2 \mathrm{~mL}$ of toluene were used. 


\section{Acetylation of phenols}

Phenols 3 gave their acetates in very good to excellent yields (Table 2). Different reaction times are required according to the nature of their substituents (see for example, entries 3, 4, $6,8)$; $o$-nitrophenol requires a higher reaction time, as well as a higher catalyst: substrate ratio, than the other examples. The intramolecular H-bond in $o$-hydroxyacetophenones wasovercome, as is demonstrated by the good yields obtained (entries 17 and 18), althoughanother similar H-bond was not (entry 16). Ortho - substituted phenols acetylate with good yields, the lower of them was obtained for the diacetylation of catechol (entry 5). The enol function in 4-hydroxycoumarin was selectively acetylated in good yield (entry 19) in a homogeneous process using acetone as solvent, because these coumarins are insoluble in toluene at room temperature. However, another example bearing vinyl $\mathrm{OH}$ (the yellow tautomer of $o$-hydroxybenzoyl benzoyl methane, entry 16) does not undergo acetylation, but a slow cyclization to flavone yielding $8 \%$ by continued stirring at room temperature. Experiments for recovering and recycling the catalyst were performed using phenol as the substrate, the reaction conditions being as defined above.

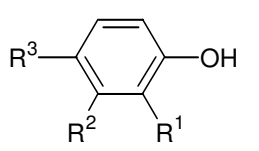

3

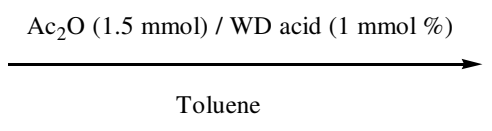

Toluene

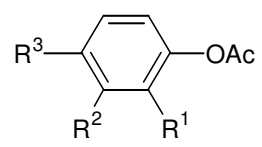

4

Table 2. WD-Acetylation of phenols with $\mathrm{Ac}_{2} \mathrm{O}$

\begin{tabular}{|c|c|c|c|c|c|}
\hline Entry & $\mathrm{R}^{1}$ & $\mathrm{R}^{2}$ & $\mathrm{R}^{3}$ & Reaction time, $\mathrm{h}$ & Yield of $4, \%$ \\
\hline 1 & $\mathrm{H}$ & $\mathrm{H}$ & $\mathrm{H}$ & 1 & $96^{\mathrm{a}}$ \\
\hline 2 & $\mathrm{Me}$ & $\mathrm{H}$ & $\mathrm{H}$ & 0.75 & 95 \\
\hline 3 & $\mathrm{OMe}$ & $\mathrm{H}$ & $\mathrm{H}$ & 0.5 & 95 \\
\hline 4 & $\mathrm{NO}_{2}$ & $\mathrm{H}$ & $\mathrm{H}$ & 5 & $93^{\mathrm{b}}$ \\
\hline 5 & $\mathrm{OH}$ & $\mathrm{H}$ & $\mathrm{H}$ & 3 & $87^{\mathrm{c}}$ \\
\hline 6 & $\mathrm{H}$ & $\mathrm{Br}$ & $\mathrm{H}$ & 1 & 99 \\
\hline 7 & $\mathrm{H}$ & $\mathrm{F}$ & $\mathrm{H}$ & 2 & 94 \\
\hline 8 & $\mathrm{H}$ & $\mathrm{NO}_{2}$ & $\mathrm{H}$ & 3 & 90 \\
\hline 9 & $\mathrm{H}$ & $\mathrm{H}$ & $\mathrm{Cl}$ & 1 & 98 \\
\hline 10 & $\mathrm{H}$ & $\mathrm{H}$ & $\mathrm{Me}$ & 0.75 & 98 \\
\hline 11 & $\mathrm{H}$ & $\mathrm{H}$ & $\mathrm{OMe}$ & 0.5 & 92 \\
\hline 12 & $\mathrm{H}$ & $\mathrm{H}$ & $\mathrm{Ph}$ & 1 & 95 \\
\hline 13 & & & & 1 & 93 \\
\hline 14 & & & & 2 & 90 \\
\hline 15 & & & & 0.5 & 98 \\
\hline
\end{tabular}

Contd... 


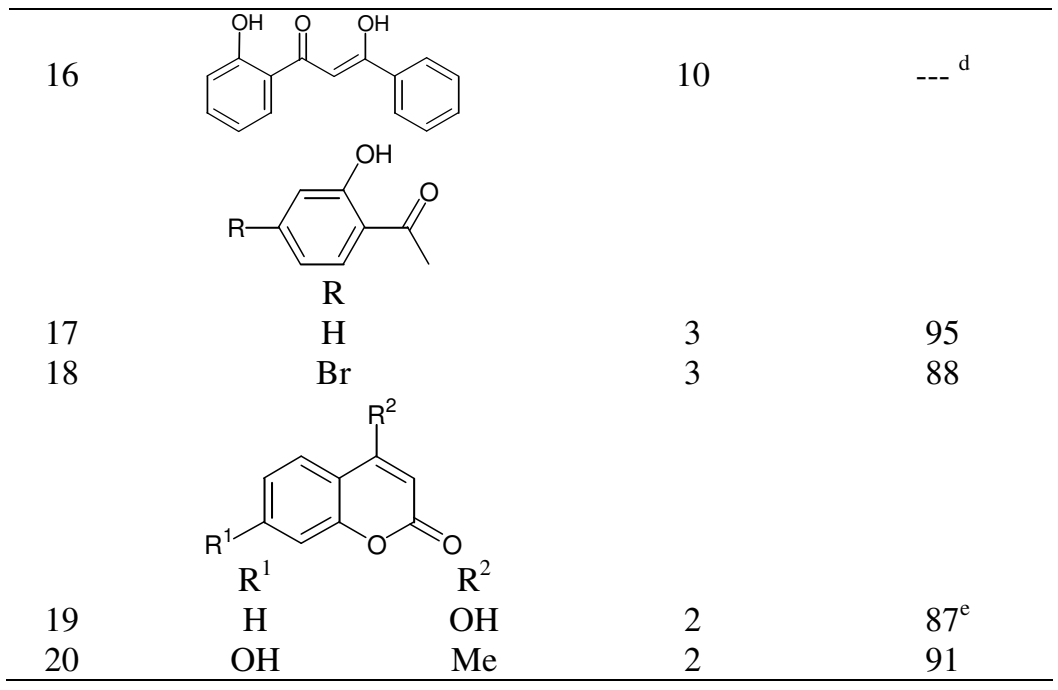

${ }^{a}$ Yields of isolated product over three subsequent batches were 95, 94, and $94 \%$, respectively.

${ }^{b} \mathrm{~A}$ ratio $5: 1$ ( $\mathrm{Ac}_{2} \mathrm{O}$ : phenol) was used. ${ }^{c}$ Yield of the diacetate. ${ }^{d}$ Flavone was isolated, see text.

${ }^{e} \mathrm{C}$-acylation was not observed. Solvent was acetone $(2 \mathrm{~mL}$, see text).

\section{Acetylation of thiols and amines: Acylation using other anhydrides}

Aromatic and aliphatic representative thiols were tested for their acetylation. In both cases the reaction is complete in about $1 \mathrm{~h}$ at room temperature, no progress was observed by extending the reaction time. Besides, some aromatic amines were tested for the reaction, requiring lower reaction time than phenol or thiophenol to obtain very good yields of the corresponding amides (Table 3 ).

Table 3. WD-Acetylation of amines and thiols with $\mathrm{Ac}_{2} \mathrm{O}$

\begin{tabular}{ccc}
\hline Compound & Reaction time, $\mathrm{h}$ & Yield of amides and thiol esters, \% \\
\hline $\mathrm{PhNH}_{2}$ & 0.25 & 98 \\
$p-\mathrm{ClC}_{6} \mathrm{H}_{4} \mathrm{NH}_{2}$ & 0.25 & 95 \\
$p-\mathrm{MeC}_{6} \mathrm{H}_{4} \mathrm{NH}_{2}$ & 0.25 & 96 \\
$n-\mathrm{C}_{16} \mathrm{H}_{33} \mathrm{SH}$ & 1 & $92^{\mathrm{a}}$ \\
$\mathrm{PhSH}$ & 1 & $98^{\mathrm{a}}$ \\
\hline
\end{tabular}

${ }^{a}$ Yields were expressed from GLC data.

Table 4. WD-Acylation of phenol and benzyl alcohol with acid anhydrides ${ }^{\mathrm{a}}$

\begin{tabular}{ccc}
\hline Acid anhydride & \% Yield of phenyl ester & \% Yield of benzyl ester \\
\hline$\left(\mathrm{MeCO}_{2} \mathrm{O}\right.$ & $96^{\mathrm{b}}$ & $98^{\mathrm{b}}$ \\
$\left(\mathrm{ClCH}_{2} \mathrm{CO}\right)_{2} \mathrm{O}$ & 93 & 96 \\
$\left(\mathrm{C}_{2} \mathrm{H}_{5} \mathrm{CO}\right)_{2} \mathrm{O}$ & 94 & 97 \\
$\left(n-\mathrm{C}_{3} \mathrm{H}_{7} \mathrm{CO}\right)_{2} \mathrm{O}$ & 90 & 92 \\
$(\mathrm{PhCO})_{2} \mathrm{O}$ & 96 & 94 \\
\hline
\end{tabular}

${ }^{\text {a }}$ Reaction time: $1 \mathrm{~h}(\mathrm{PhOH})$ or $0.75 \mathrm{~h}\left(\mathrm{PhCH}_{2} \mathrm{OH}\right) ; 20^{\circ} \mathrm{C}$ temperature.

${ }^{\mathrm{b}}$ Results included for comparison purposes (Tables $1 \& 2$ ). 
Furthermore, different both aliphatic and aromatic acid anhydrides were also used for performing the catalytic WD-acylation of phenol and benzyl alcohol as the selected substrates (Table 4). Reaction conditions were those of the acetylation of phenol and benzyl alcohol, respectively.

\section{Conclusions}

The procedure described above provides a useful alternative for the acetylation of alcohols, phenols, amines, and thiols in mild conditions. It is general, rapid, selective, inexpensive, and environmentally friendly. The use of Wells-Dawson heteropolyacid allows the acetylation to occur efficiently, with very good to excellent yields and high purity of the products, these advantages being especially valuable for industrial applications. Studies are in progress in our laboratories in relation to the use of supported catalysts.

\section{Acknowledgments}

Financial support from Agencia Nacional de Promoción Científica y Tecnológica, Fundación Antorchas (Argentina) and Universidad Nacional de La Plata is gratefully acknowledged. H. J. T., G. B., and G. P. R. are members of CONICET.

\section{References}

1. (a) Wilkinson S G, Comprehensive Organic Chemistry, Barton D and Ollis W D, Ed. Alcohols, Pergamon: Oxford, 1979; Vol. 1, pp. 579-582. (b) Whiting D A, Comprehensive Organic Chemistry, Barton D and Ollis W D, Ed. Phenols, Pergamon Oxford, 1979, Vol. 1, pp. 708-709, 734-735 . (c) Malpass J R, Comprehensive Organic Chemistry, Barton D and Ollis W D, Ed. Aliphatic, Acyclic and Cyclic Amines. Pergamon: Oxford, 1979; Vol. 2, pp. 39-40, 49-50. (d) Lindsay R J, Comprehensive Organic Chemistry, Barton D and Ollis W D, Eds. Aromatic Amines. Pergamon: Oxford, 1979; Vol. 2, pp. 159-161. (e) Larock R C, Comprehensive Organic Transformations: A Guide to Functional Group Preparations, Wiley, New York, 1989, pp. 980-981. (f) March J, Advanced Organic Chemistry. Reactions, Mechanisms and Structure, Wiley New York, 1992, pp. 392-393, 409, 418-419.

2. Greene T W, Wuts, P G M, Protecting Groups in Organic Synthesis, Wiley, New York, 1991, pp. 87-89, 162-163, 298, 351.

3. (a) Horton D, Org. Synth. 1973, Coll. 5, 1-6. (b) Zhdanov R I and Zhenodarova S M, Synthesis, 1975, 222-245. (c) Scriven E F V, Chem. Soc. Rev. 1983, 12, 129-161. (d) Sano T, Ohashi K and Oriyama T, Synthesis, 1999, 1141-1144.

4. Vedejs E, Bennets N S, Conn L M, Diver S T, Gingras M, Lin S, Oliver P A and Peterson M J, J. Org. Chem. 1993, 58, 7286-7289.

5. Vedejs E and Daugulis O, J. Org. Chem, 1996, 61, 5702-5703.

6. D'Sa B A and Verkade J G, J. Org. Chem. 1996, 61, 2963-2966.

7. (a) Jin T S, Ma Y R, Zhang Z H and Li T S, Synth. Commun. 1998, 28, 3173-3177 and references cited therein. (b) Pansare S V, Malusare M G and Rai A N, Synth. Commun. 2000, 30, 2587-2592. (c) Mohammadpoor-Baltork I, Aliyan H and Khosropour A R, Tetrahedron, 2001, 57, 5851-5854 and references cited therein. (d) Sabitha G, Subba Reddy B V, Srividya R and Yadav J S, Synth. Commun, 1999, 29, 2311-2315. (e) Chakraborti A K, Sharma L, Gulhane R and Shivani, Tetrahedron, 2003, 59, 76617668. (f) Dalpozzo R, De Nino A, Maiuolo L, Procopiou A, Nardi M, Bartoli G and Romeo R, Tetrahedron Lett., 2003, 44, 5621-5624. (g) Chakraborti A K and Gulhane R, Tetrahedron Lett., 2003, 44, 6749-6753. (h) Carrigan M D, Freiberg D A, Smith R C, Zerth H M and Mohan R S, Synthesis, 2001, 2091-2093. 
8. (a) Karimi B and Seradj H, Synlett., 2001, 519-520. (b) Ishihara K, Kubota M and Yamamoto H, Synlett., 1996, 265-266. (c) Hagiwara H, Morohashi K, Suzuki T, Ando M, Yamamoto I and Kato M, Synth. Commun. 1998, 28, 2001-2006. (d) Hagiwara H, Morohashi K, Sakai H, Suzuki T and Ando M, Tetrahedron., 1998, 54, 5845-5852.

9. (a) Ballini R, Bossica G, Carloni S, Ciaralli L, Maggi R and Sartori G, Tetrahedron Lett., 1998, 39, 6049-6052. (b) Curini M, Epifano F, Marcotullio M C, Rosati O and Rossi M, Synth. Commun., 2000, 30, 1319-1329. (c) Kumareswaran R, Pachamuthu K and Vankar Y D, Synlett, 2000, 1652-1654. (d) Habibi M H, Tangestaninejad S, Mirkhani V and Yadollahi B, Tetrahedron, 2001, 57, 8333-8337. (e) Tayebee R and Alizadeh M H, Monatshefte fur Chemie., 2006, 137, 1063-1069. (f) Alizadeh M, Kermani T and Tayebee R, Monatshefte fur Chemie., 2007, 138, 165-170.

10. Kozhevnikov I V, Catal. Rev.-Sci. Eng., 1995, 37, 311-352.

11. (a) Baronetti G T, Briand L, Sedran U and Thomas H, Appl. Catal. A: General., 1998, 172, 265. (b) Jander G and Banthien H Z, Z. Anorg. Allg. Chem. 1936, 229, 142.

12. Lyon D K, Miller W K, Novet T, Domaille P J, Evitt E, Jonson D C V and Finke R G, J. Am. Chem. Soc., 1991, 113, 7209.

13. (a) Romanelli G P, Autino J C, Baronetti G and Thomas H J, Synth. Commun., 2004, 34 (21), 3909-3914 and references cited therein. (b) Romanelli G P, Baronetti G, Thomas H J and Autino J C, Tetrahedron Lett., 2002, 43, 7589-7591. (c) Romanelli G P, Bennardi D, Ruiz D M, Baronetti G, Thomas H J and Autino J C, Tetrahedron Lett., 2004, 45, 8935-8939. 


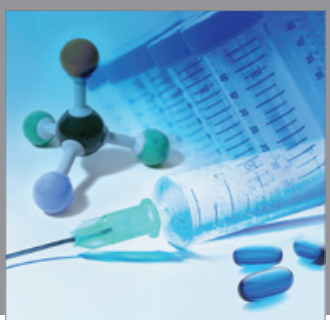

International Journal of

Medicinal Chemistry

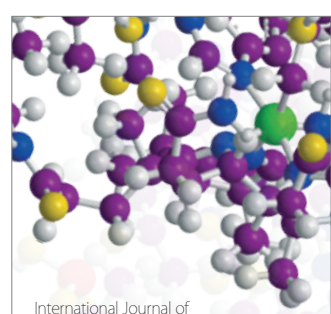

Carbohydrate Chemistry

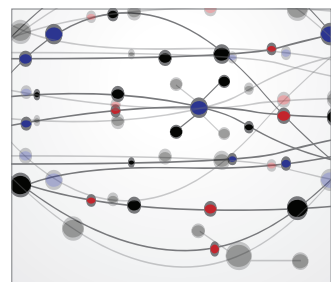

The Scientific World Journal
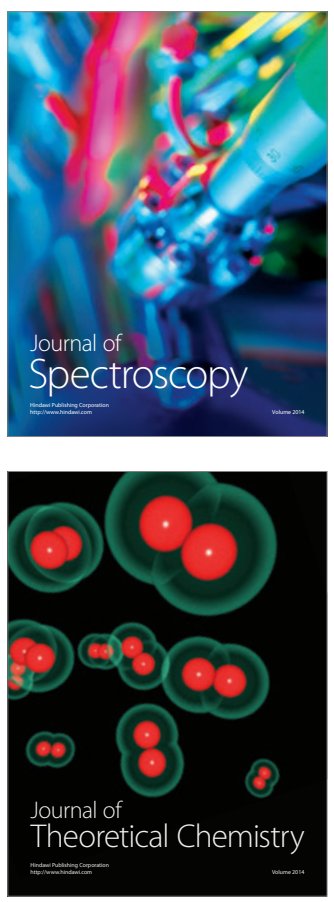
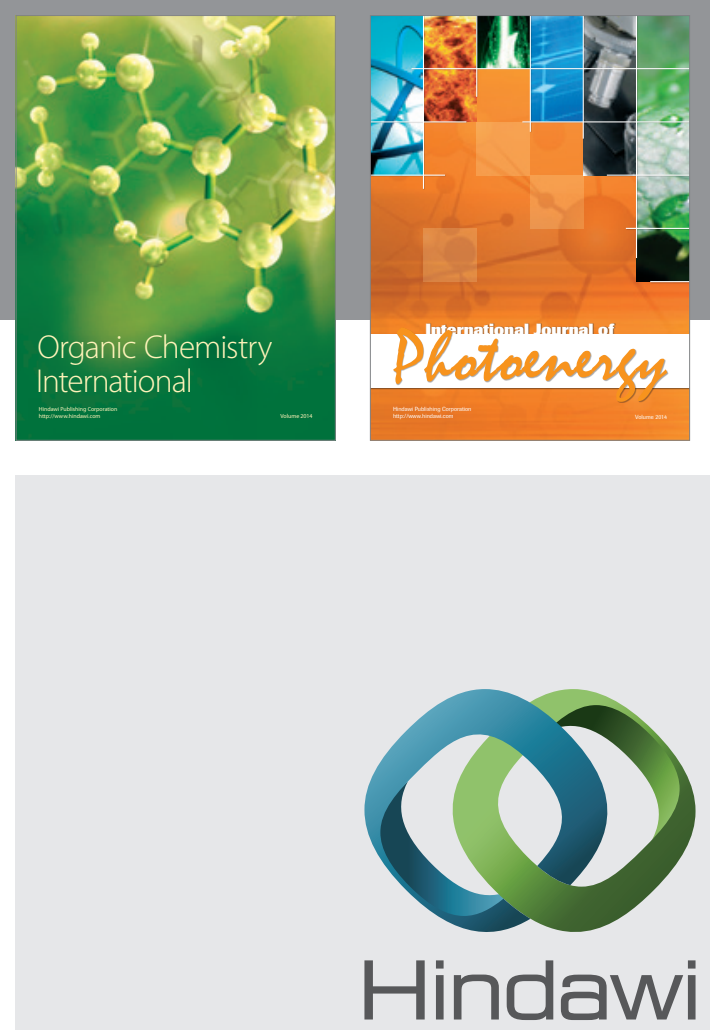

Submit your manuscripts at

http://www.hindawi.com
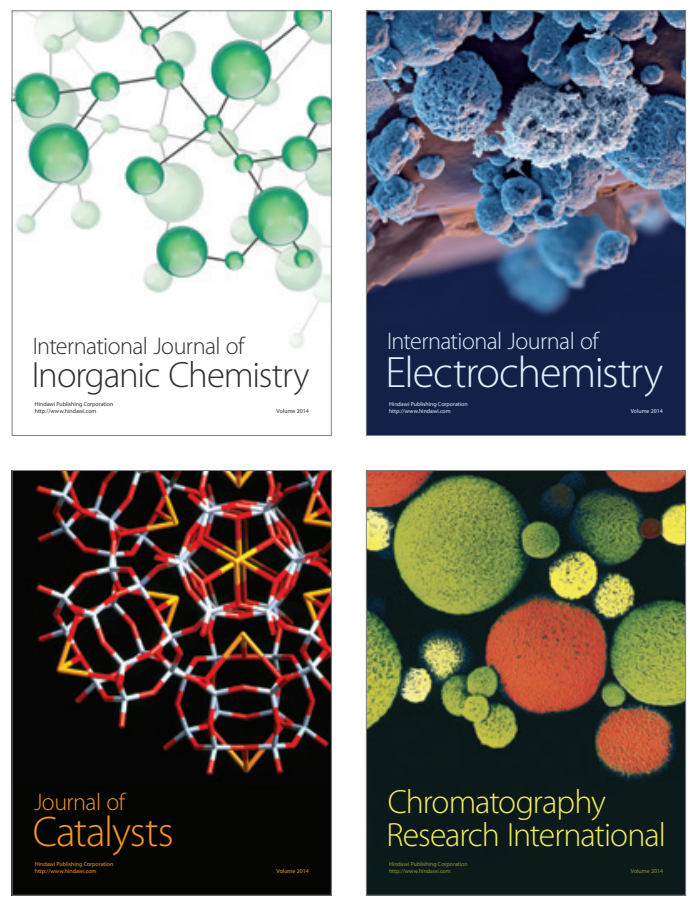
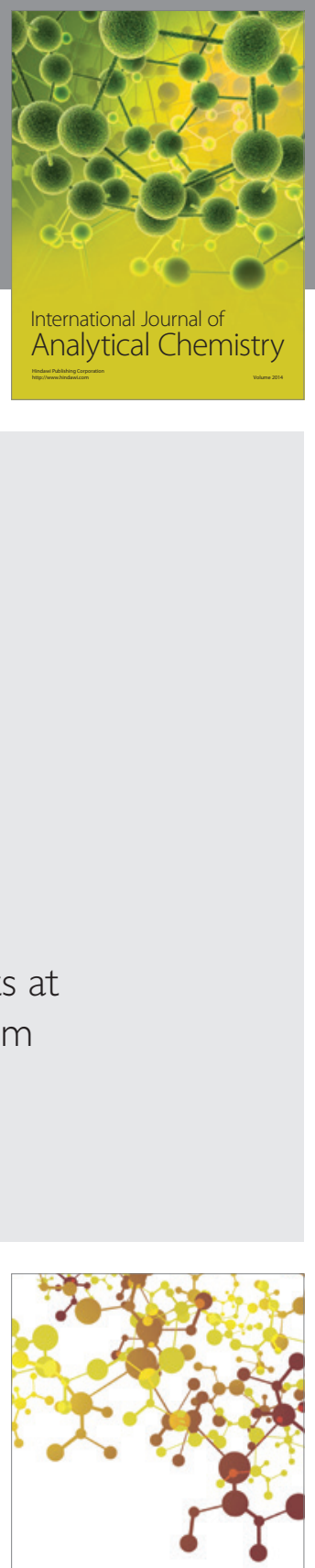

Journal of

Applied Chemistry
